\title{
Macro-environmental Analysis of Auto Parts Industries' Development of China Based on PEST Method
}

\author{
Xiaoyan Du \\ Hubei University of Automotive Technology \\ ShiYan, Hubei, China, 442002
}

\begin{abstract}
Under the conditions of the global economic downturn and increasingly intense competition in the automotive market, China, the world's largest auto parts market, attracts more and more attention. Based on PEST method, this paper systematically analyzes the political environment, economic environment, social environment and technological environment on the development of Chinese auto parts industry, which is intended to provide some advices for auto parts enterprises, including the supply reform, technological innovation, market development and so on.
\end{abstract}

Keywords-Auto Parts Industry; PEST Method; Macroenvironment; China

\section{INTRODUCTION}

In the past few years, as the advancing and improving of the third industrial involution all over the world, strategies such as "Industry 4.0" " Industrial internet"" e-F@ctory" "Made in China 2025" "internet +" are respectively implemented in German, American, Japan and China. The auto parts industries would face many new challenges and opportunities due to the changes of global economic situation, the newly emerged market competitive pattern, and the breakthroughs in new energy technologies and internet. It is necessary to analysis the external environment of the China's auto parts industries in order to enable the auto parts enterprises to successfully grasp the opportunities and meet the challenge, initiatively adapt to the China's new normal.

\section{POLITICAL ENVIRONMENT}

\section{A. Industry Regulatory System and the Regulatory Authorities}

At present, the auto parts industries in China has already format a market competitive pattern. On the one hand, enterprises independently and market-oriented manage their business. On the other hand, government functional departments administrate the market according to the law. National Development and Reform Commission, Ministry of Industry and Information Technology is the administrative department of the auto parts industries, mainly responsible for making industrial policies, guiding technological innovation, approving and managing megaprojects of investment. General Administration of Quality Supervision, Inspection and Quarantine of the People's Republic of China is responsible for industry technology, quality control and other work. National Automotive Standardization Technical Committee is responsible to discuss the industry and national standards, while Ministry of Industry and Information Technology is responsible for approving industry and national standards. State Administration for Industry and Commerce is responsible for market supervision management. Environmental protection departments are responsible for regulating the environmental pollution caused by manufacturing. China Association of Automobile Manufactures and various provincial branch is the selfregulatory organization of the auto parts industries, its basic function is to provide investigation, suggestion, selfmanagement, information guidance, consultation services, international communication and other services.

\section{B. The Mainly Industry Regulations And Policies}

Auto parts industries are key factors supporting the automobile industry developing healthy and sustainable. It is a effective and strong factor to promote the industry and job market. In order to further promote the sustainable development of auto parts industries, the relevant government departments issued a series of policies and guidelines to support auto parts and automobile manufacture industry restructuring, industrial upgrading, automobile consumption promoting, industry management regulating in the past five years. Policies and guidelines could be concluded in the following aspects:

- Encourage industrial restructuring and upgrading, promote corporate mergers and acquisitions. In October 2010, the Ministry of Industry and Information Technology issued "Basic Mechanical parts industry revitalization plan" to setup specific measures to promote the basic mechanical parts industry upgrading; in January 2013, the Ministry of Industry and Information Technology and the National Development and Reform Commission and other ten departments issued "guidelines on accelerating key industries and enterprises mergers and acquisitions", rank the automobile industry as the first of the nine industries accelerating mergers and 
acquisitions, actively promote auto parts corporate mergers and acquisitions.

- Energy saving and consumption reducing. In August 2013, the State Council issued "guidelines on accelerating the development of energy-saving environmental protection industry" which pointed out that eliminate yellow cars and old cars, research on the policies measures to expand the environmental products consumption; in October 2014, the Ministry of Industry and Information Technology, and the National Development and Reform Commission and other three ministries issued "Notice of strengthening average fuel consumption management of automobile corporate" which put forward that " limit the production of automobiles which does not reach the target of fuel consumption" and other four policy measures.

- Break the monopoly. In September 2014, the Transport Ministry and other nine ministries issued "seek advice on the promotion of automotive repair industry upgrading and improving service quality " It will help to get rid of the current status of automobile companies and $4 \mathrm{~S}$ shop monopolize original auto parts market, meanwhile conducive to the development of third-party auto repair companies, and facilitating the auto parts market develop toward to transparent and standard market.

- Standard Specification. In December 2014, the Ministry of Industry and Information Technology issued "standard of lithium-ion battery industry", this draft proposed a strict control of capacity expansion on lithium-ion battery projects with low level of technology. The standard specification applicable for all types of upstream and downstream enterprises in lithium-ion battery industry, including cathode material, anode material, separator, electrolyte (containing an electrolyte), batteries and other enterprises. It formulates detailed specification and provision to the industrial layout, invest new projects, the scale of output, technological processes, product quality, comprehensive utilization of resources and environmental protection.

- Encourage the development of new energy automobiles. In June 2012, the State Council issued "energy-saving and development plan of new energy automobile industry(2012-2020)", put forward that new energy automobiles, power batteries and key components to reach the international advanced technology level, strengthen the research of key technology and expand the effort to the research environmental technology.

\section{The Impact of Policy Environment to the Auto Parts Industries}

Faced with the challenges of the global energy crisis and rising raw material and labor costs, related auto parts industries policy would be to the main driving force to promote industrial upgrading and improve the efficiency of industrial scale and core competitiveness, and to guide a more environmental, more energy efficient and more standard way of developing. But for the traditional auto parts companies which is production capacity outdated, small economic scale, and in the bottom of the industry value chain, developing following the trend would be the key to survive.

\section{ECONOMIC ENVIRONMENT}

\section{A. Analysis of Global Economic Environment}

Affected by the international financial crisis, the European debt crisis, the aging of the labor force, slow labor productivity growth and other factors, the global economy changed from a rapid development period before the financial crisis to a deep structural adjustment period. Most of the economies are facing a low inflation rate, some economies are now sliding into deflation. For example: in December 2014, the producer price index (PPI) rate in the US hit the biggest decline in three years, the PPI of euro zone has lasted 17 months in negative growth from July 2013. In future, the global economy will remain overall weak and slow recovery, the economic growth rate will be less than $3 \%$. The global economy will be subject to three factors: Firstly, the energy and commodity prices decreasing lead to global deflation risk; Secondly, the dollar has entered into a strong cycle, will not only accelerate the flight of capital, resulted in capital flight among emerging economies, and increasing the risk of overseas dollar-denominated debt of emerging economies, and push up global financing costs; Thirdly, the risk of emerging economies' back overflow effect " is outstanding.

\section{B. Analysis of Domestic Economic Environment}

After 30 years of rapid growth since the Reform and Opening, China has become the world's second largest economy only next to the United States economy. In 2014, the national GDP first break 60 trillion yuan and reached 63.6463 trillion yuan, with an increase rate of $7.4 \%$, growth rate slipped to a new low since 1990 . At present, the Chinese economy is experiencing a change from relying on consumption, investment and exports, the short-term "troika" of the economic growth to rely on capital, labor, resources, technology innovation, system innovation which support a long-term growth. Traditional force of economic development gradually weakened, while the force of new normal economic have not been strong yet, coupled with the strong dollar, the global trade policy changes and other uncertain factors, Chinese economy would facing downward pressure in the next period. At present, China's economic development showed the following characteristics: Firstly, a continuous decline in economic growth; Secondly, economic growth troika show weakness; Thirdly, the price level continued to decline; Fourthly, economic development is expected to be worse. To accelerate the pace of economic transformation and upgrading, to seek for new economic growth point, the State Council and relevant departments are actively promoting "The Belt and Road", "Asian Infrastructure Investment Bank" and other economic strategies. As the implementation of the above strategies, 
China's economy is expected to experience a new round of steady growth period.

\section{The Impact of Economic Environment to the Auto Parts Industries}

Looking through the global and domestic economic environment, the slow growth of economic and increasing deflation pressure would become the main theme of the next period of time. In the level of supply, the fall of oil and other commodity prices may ease the pressure of increasing production cost and logistic cost that manufacturing enterprises are facing. In the level of demand, on the one hand, decreasing manufacturing costs and crude oil price directly reduce product prices and cost of using cars, which can promote the increase demand of automobile and auto parts; on the other hand, although the global economy is facing downward pressure, but still has some space for growth. With a series of policies boosting the economy and stimulating consumption, the demand of automobiles and auto parts could effectively increase. In conclusion, the auto parts industries still faces many opportunities at the current economic situation.

\section{SOCIAL ENVIRONMENT}

\section{A. The Increasing Level of Urbanization}

Urbanization is an important symbol of a country's modernization, the increasing level of urbanization is conducive to improve the consumption structure, the release of the consumption potential, and will bring urban infrastructure, public service facilities, residential construction and other huge investment demand, which will provide continuous driving force of economic development. At present, China's population urbanization rate was $53.7 \%$, household register population urbanization rate is only about $36 \%$, far below the average rate of $80 \%$ in developed countries and also lower than the average rate of $60 \%$ in other developing countries which have approximate income per capita. This shows a large space for development. In March 2014 the State Council issued "new national urbanization plan (2014- 2020)", which pointed out that by 2020 , resident population urbanization rate would reached $60 \%$, household register population urbanization rate would reached about $45 \%$, and aims to transfer 100 million agricultural population to live in towns.

\section{B. Gradually Changing in Lifestyles and Consuming Attitude}

Between 2012-2014 years, China's per capita disposable income of residents is 13,805 yuan, 18,311 yuan and 20,167 yuan respectively, with an average annual growth rate of more than $10 \%$. Increasing in income level directly changed people's lifestyles and consuming attitude, making people pay more attention to the safety and comfortable of cars and auto parts. At the same time, the popularize of modern communications technology and manufacturing technology encourage people to pay more attention to product intelligence, control ability, and also cultivating the individual needs of consumers.

\section{Formation of Automobile Culture}

Automobile culture is a distinctive product image and product positioning in consumers' mind after many years of marketing. The impaction of automobile culture connotation to consumers, to some extent, much larger than the research and development of new automobile models. Currently the advanced automobile manufacturing countries have already formed its unique automobile culture. For example: the strict of German car, the romantic of French car, the noble of British cars, the smart of Japanese cars. With the rapid development of China's domestic automobile industry, the harmonious coexistence culture of people, automobile and road began to take shape, which will become an important factor affecting consumers' buying behavior.

\section{The Impaction of Social Environment to Auto Parts Industries}

The large remaining space of urbanization level increasing will continuously provide driving force to automobile and auto parts markets; changing in lifestyles and consumer attitudes will propose higher requests to automobile and auto parts product in reliability, user-friendly, personalized and other aspects. The formation of automobile culture, on the one hand, cultivates consumer loyalty to the products; on the other hand, it will also increase the difficulty for auto parts companies to take part in the global procurement system of automobile enterprises.

\section{TECHNOLOGICAL ENVIRONMENT}

\section{A. The Combination of Traditional Manufacturing and Internet Create "Intelligent Manufacturing"}

Currently, the advanced industrial countries are actively exploring the deeply integration of Internet and traditional manufacturing. The integration have accumulated rich experience in Internet-based cloud computing, big data and other core technology development, and also in policy supporting and technology industrialization. Especially the "Industry 4.0" "intelligent connected manufacturing" "digital factory" in German, "internet factory" "brilliant factory" in the US, and e-F@ctory in Japan have great influence.

To actively respond to these challenges, our government has recently issued the "Internet + " plan and "Made in China 2025" plan. The "Internet + industry" as an important part of "Internet + " strategy aims to improving traditional industries (including auto parts manufacturing) on highly intelligent, networked, digitized and automation, and promoting the mobile Internet, cloud computing, big data, Internet of things combine with modern manufacturing. Thus, it is important to lay a solid industrial foundation for "2025 Made in China."

\section{B. Energy-saving and New Energy Automobile Technology Become Mainstream}

Due to the increasing environment and energy pressure, and the changing of consumer attitudes, the market share of the traditional automobile industry will gradually be replaced by new energy automobile industry. For example: the United States currently formed an annual 100,000-scale of new 
energy automobile market; Japan government proposed a ambitious aim that more than $80 \%$ of new sold automobiles are new energy automobiles by 2020; In China, the Ministry of Communications proposed that by the year 2020, new energy automobiles in the transportation industry would format market scale, the total number of new energy automobiles should reach 300,000 , the contribution of new energy automobiles to the energy-saving in urban transport reach $20 \%$.

Tremendous market potential promoting the development of energy-saving and new energy automobile technology, currently it is mainly Europe, Japan and the US lead the development of new energy automobile, and they have different emphases. For example: the US focused on resolving the oil dependence and ensuring oil security; Europe focused on reducing greenhouse gas emission; Japan focused on both guaranteeing energy security and improving industrial competitiveness. At present, China's new energy automobile industry has established a "pure electric drive" technology direction, make effort to break through the battery, motor and electronic control technology, promote Battery Electric Vehicles and Hybrid Electrical Vehicle industrialization, achieve the leaping development of automobile industry.

\section{The Impact of Technological Environment to Auto Parts Industries}

The deeply integration of Internet and auto parts manufacturing would lay the foundation for distributed network innovation, collaborative innovation, intelligent manufacturing and intelligent logistics. It is benefit for the traditional auto parts companies accelerating the pace of upgrading, and providing the possibility for the realization of corner overtaking. Energy-saving and the industrialization of new energy automobile technology would propose a higher requirement on updating and light weighting to the auto parts products.

\section{CONCLUSION}

By macro-environmental analysis based on pest method, We have found that the current macro environment brought both opportunities and threats to auto parts industries' development of China.China's government and auto companies need to grasp the opportunity, change our own weaknesses, avoid the threat, and ultimately to achieve better and faster development of auto parts industry.

\section{REFERENCES}

[1] Peters E D. The Auto Parts-Automotive Chain in Mexico and China: Co-operation Potential?[J]. China Quarterly, (2012), 209(209):82-110.

[2] Yang Q, Chen Y. Auto parts demand forecasting based on nonnegative variable weight combination model in auto aftermarket $[\mathrm{C}] / /$ Management Science and Engineering (ICMSE), 2012 International Conference on. IEEE, (2012):817-822.

[3] Daville-Landero S L. The evolution of the auto parts industry in Querétaro, 1993-2008[J]. Economía Sociedad Y Territorio, (2012), 12.
[4] Newman R G. The second wave arrives: Japanese strategy in the U.S auto parts market[J]. Business Horizons, (1990), 33(4):24-30.

[5] Santucci M. Globalization of the Auto Parts Industry[J]. Journal of International Marketing, (1997), 5(3):85-89.

[6] Hong X. Logistics Optimization in Auto Parts Enterprises: In the Case of Dongfeng Auto Parts Enterprises[C]// Information Management, Innovation Management and Industrial Engineering (ICIII), 2010 International Conference on. IEEE, (2010):130-133. 